\title{
Long-chain $n-3$ fatty acid composition of seafood commonly eaten in the UK
}

\author{
M. V. P. James ${ }^{1}$, K. D. Flint ${ }^{1}$ and C. H. S. Ruxton ${ }^{2}$ \\ ${ }^{1}$ Young's Seafood Ltd, Ross House, Wickham Road, Grimsby DN31 3SW, UK and ${ }^{2}$ Nutrition Communications, \\ Front Lebanon, Cupar KY15 4EA, UK
}

Experts believe that very-long-chain $n-3$ fats (LC-PUFA) are beneficial for health and that intakes should rise to approximately 0.45 g/d (two portions of fish per week, one of which is oily) ${ }^{(1)}$. However, focusing advice on oily fish consumption has raised questions about sustainability ${ }^{(2)}$. The present study measured LC-PUFA levels in a variety of fish and shellfish, as sold (i.e. with skin, bones, head and shells removed), to help inform future nutrition advice.

Fatty acids (FA) were obtained from standardised raw fish samples using petroleum ether (boiling range $40-60^{\circ} \mathrm{C}$ ), which were then saponified and esterified to yield the methyl esters of the FA. The methyl esters were separated by GC and identified by comparison with a reference set of FA. The number of duplicate samples ranged from three to forty. The findings ( $\mathrm{g} / 100 \mathrm{~g}$ raw fish as sold) are presented in the Table:

\begin{tabular}{|c|c|c|c|c|c|}
\hline Fish species & No. samples & Total fat & DHA & EPA & Total LC-PUFA $\dagger$ \\
\hline Sea bass (Dicentrarchus Labrax) & 9 & 8.41 & 0.67 & 0.50 & 1.28 \\
\hline Cold-water prawns* (Pandalus Borealis) & 25 & 0.70 & 0.14 & 0.16 & 0.30 \\
\hline Pink salmon (Oncorhynchus gorbuscha) & 18 & 1.54 & 0.22 & 0.11 & 0.36 \\
\hline Coley (Pollachius virens) & 13 & 0.54 & 0.18 & 0.06 & 0.25 \\
\hline Yellowfin tuna (Thunnus albacares) & 17 & 2.21 & 0.23 & 0.06 & 0.32 \\
\hline Cod (Gadus morhua) & 40 & 0.48 & 0.16 & 0.08 & 0.24 \\
\hline Haddock (Melanogrammus aeglefinus) & 35 & 0.55 & 0.14 & 0.11 & 0.26 \\
\hline Alaskan pollock (Theragra chalcogramma) & 40 & 0.53 & 0.14 & 0.11 & 0.27 \\
\hline Scampi (Nephrops norvegicus) & 23 & 0.47 & 0.08 & 0.09 & 0.18 \\
\hline Mussels (Mytilus edulis) & 3 & 1.90 & 0.26 & 0.40 & 0.69 \\
\hline
\end{tabular}

*Peeled and cooked. †Chain lengths $>20$.

The results show that certain species of white fish and shellfish contain reasonable levels of LC-PUFA and could help consumers meet LC-PUFA recommendations. Broadening current advice on fish consumption to highlight the LC-PUFA content of different fish species, many of which are low in total fat, may contribute to sustainability as well as health.

1. Scientific Advisory Committee on Nutrition (2004) Advice on Fish Consumption: Benefits and Risks. London: Food Standards Agency.

2. Food Standards Agency (2009) Review of agency's advice on fish consumption. Public consultation. www.food.gov.uk/consultations/consulteng/2009/ advicefishconsumption (accessed January 2009). 